\title{
REDOX CAPACITY OF APO MAMMALIAN FERRITIN
}

\author{
Gerald D. Watt ${ }^{1}$ and Richard B. Frankel ${ }^{2}$ \\ 1Department of Chemistry and Biochemistry \\ Brigham Young University \\ Provo, UT 84602 \\ 2Department of Physics \\ California Polytechnic State University \\ San Luis Obispo, CA 93407
}

\section{INTRODUCTION}

Mammalian ferritin is a roughly spherical 24 subunit protein $130 \AA$ across containing a hollow interior $70 \AA$ across which can contain up to 4500 iron atoms in the form of an $\mathrm{FeOOH}$ mineral core (1). The function of the mammalian protein is to provide the cell with a readily mobilized, biologically compatible form of iron necessary for various metabolic purposes while simultaneously strongly binding iron and thereby protecting the cell from deleterious effects promoted by free cellular iron $(2,3,4)$. The structure of the apo ferritin molecule has been reported at $2.8 \AA$ resolution (1) and clearly shows the subunit arrangement and the hollow central core where the iron mineral is sequestered. The subunits are arranged so that 8 and 6 channels leading from the exterior to the core are formed along 3-fold and 4-fold symmetry axes, repectively. The 4-fold channels are essentially hydrophobic in nature, being lined with leucine amino acid residues, while the 3 -fold channels are rendered hydrophylic by carboxylate groups lining the channel interior. These structural features have led to the hypothesis that $\mathrm{Fe}^{2+}$, reductants, oxidants and chelators enter and leave the ferritin core through these channels. Recent metal ion binding and binding competition studies $(5,6,7)$ have implicated the hydrophylic channels as binding sites for $\mathrm{Fe}^{2+}$ (as well as other metal ions that interact with ferritin) because 8 binding sites are observed, numerically equivalent to the 8 channels along the 3 -fold symmetry axes. The nature of the 4-fold channels remains undefined but a reasonable hypothesis is that these channels serve as reductant and oxidant entry ports or sites for redox reactions which alter the redox status of the ferritin core during iron release and iron deposition. Thus, a significant aspect of ferritin function is concerned with the role that these channels play in the regulation of cellular iron flux by the ferritin molecule. 
Iron deposition and release involve electron transfer reactions either from iron (during iron deposition) or to iron (during iron release). If penetration by a reductant into the core of ferritin is a requirement for iron reduction, then only those reagents with sizes near or less than the channel dimensions will be effective reductants; conversely large reductants will be ineffective in mobilizing iron. Ideally, nearly isopotential reagents with $\mathrm{E}_{1 / 2}$ values more negative than the ferritin core (8) should be used to examine the redox response of the ferritin core to reduction by reagents of varying size in order to minimize large changes in the free energy driving force. A series of organic reductants approximating these conditions was examined (9) and the size of the reductant was found to be immaterial in its ability to reduce the ferritin core. Molecules with dimensions exceeding, by several fold, the nominal diameter of the ferritin channels were in some cases, more effective in reducing the core than smaller members of this series. The charge of the reductant may also be an important factor because small negatively charged reagents reacted more slowly than positively charged reductants. We have reported (10) that large redox proteins, much larger than the channel openings, (in some cases larger than the ferritin subunits!) alter the redox status of the ferritin core as effectively as the smaller molecules. These results clearly exclude channel entry by the reductant as a viable mechanism for electron transfer and in some cases even exclude ferritin subunit dissociation-reassociation as a mechanism for reductant contact with the ferritin core particle.

The question raised by these results is, how do redox reagents separated from the ferritin core by a $20-30 \AA$ thick protein shell transfer electrons to the ferritin interior? Two possible processes include: a) a redox process that is mediated by the $\mathrm{Fe}^{2+} / \mathrm{Fe}^{3+}$ couple arising from mobile iron bound in the channels or loosely attached to the core itself; and b) an inherent redox capacity of apo ferritin itself. We have previously demonstrated $(7,11)$ the feasibility of the first process by showing that when $57 \mathrm{Fe}^{2+}$ is added to the holo ferritin, electron transfer occurs at the core resulting in $57 \mathrm{Fe}^{3+}$ and $\mathrm{Fe}^{2+}$ retained within the core. Thus, a cycle can be imagined whereby a reductant reduces a mobile channel or core bound $\mathrm{Fe}^{3+}$ to $\mathrm{Fe}^{2+}$ which then migrates to and undergoes electron transfer with the ferritin core, becoming oxidized back to $\mathrm{Fe}^{3+}$ to begin another cycle. The second process for reducing the ferritin core requires that electrons be transferred through the ferritin protein shell by electron tunneling or by some other protein mediated process. Current research on electron tunneling in biological molecules $(12,13)$ suggests that electron tunneling through $30 \AA$ of the ferritin protein shell is only marginally possible. With this unfavorable conclusion in mind we have begun to examine ferritin more closely for alternate processes that provide for long distance electron transfer through the protein shell.

During measurements of $\mathrm{Fe}^{2+}$ binding to apo ferritin, we observed (11) that even under strictly anaerobic conditions as much as $25 \%$ of the added $\mathrm{Fe}^{2+}$ is converted to $\mathrm{Fe}^{3+}$. Careful measurements demonstrated that only $\mathrm{Fe}^{2+}$ and apo ferritin were present forcing us to infer that apo ferritin posesses inherent oxidative capacity. Microcoulometric measurements of anaerobic, iron-free apo ferritin (exhaustively dialysed with thioglycollic acid to ensure removal of all transition metal ions) have now demonstrated further that up to six electrons can be transferred to the 24 subunit molecule. Optical spectroscopy shows a decrease in absorbance for the reduced relative to the oxidized state in the $330-$ 
$450 \mathrm{~nm}$ range. In addition, we have found that $\mathrm{Fe}$ III cytochrome $\mathrm{c}$ and plastocyanin are reduced to $\mathrm{Fe} I \mathrm{II}$ cytochrome $\mathrm{c}$ and $\mathrm{Cu} \mathrm{I}$ by the reduced form of apo ferritin. While it is necessary to confirm these results by further experimentation, we believe that the present evidence supports an inherent redox capacity of the apo ferritin protein structure. Such a view would require that, most likely, the aromatic amino acids are involved in some unprecedented manner. Anomalous fluorescence (14) and spectroscopic behavior (15) of these groups in ferritin is well documented.

\section{MATERIALS AND METHODS}

Apo mammalian ferritin (apo MF) was prepared from holo ferritin by the thioglycollic acid method (16). Because apo MF prepared in this manner still retains traces of iron, a second iron removal step was utilized. Apo MF was made anaerobic, reduced with excess reduced methyl viologen (MV) or with sodium dithionite (DT) and MV for 30 min followed by addition of dipyridyl (dipyd) to chelate the $\mathrm{Fe}^{2+}$ produced during reduction. The resulting solution was passed through a G-25 Sephadex column to separate the apo ferritin from excess reductant and $\mathrm{Fe}$ (bipyd) $3^{2+}$. Reduced apo mammalian ferritin (apo $\mathrm{MF}_{\mathrm{r}}$ ), apo mammalian ferritin with the protein shell reduced, was prepared by conducting the above procedure under anaerobic conditions provided by a Vacuum Atmospheres glove box (Argon $<1 \mathrm{ppm} \mathrm{O}_{2}$ ) and oxidized apo mammalian ferritin (apo MF), with the protein shell in the native or oxidized form, was prepared by stirring apo $\mathrm{MF}_{\mathrm{r}}$ in air for several hours.

Oxidized apo MF was fractionally precipitated by either ammonium sulfate addition or by $\mathrm{pH}$ adjustment to either side of the isoelectric point. The precipitated protein was isolated by centrifugation and redissolved in 0.025 Tes $\mathrm{pH} 7.5$. Absorption spectra in the $220-700 \mathrm{~nm}$ region were taken and $\mathrm{A}_{280} / \mathrm{A}_{252}$ and $A_{280} / A_{340}$ values were determined for apo ferritin samples variously precipitated by the methods discussed above. Dialysis of apo MF in $67 \%$ acetic acid was conducted for 24 hours at $6^{\circ} \mathrm{C}$ followed by spectroscopic measurements in both this same solvent and that adjusted slowly to $\mathrm{pH} 7.25$.

Microcoulometry of anaerobic apo MF was conducted (17) as previously described. Sedimentation analysis of oxidized apo $\mathrm{MF}$ at $25 \mathrm{mg} / \mathrm{ml}$ was conducted in a double sector cell in a Beckman Model E ultracentrifuge equipped with a UV scanner set at $400 \mathrm{~nm}$.

\section{RESULTS}

At high protein concentrations $(20-100 \mathrm{mg} / \mathrm{ml})$ apo $\mathrm{MF}$ displays a pale yellow color which results from the aromatic amino acid absorption band centered at $280 \mathrm{~nm}$ tailing off well into the visible spectral region, as shown in Figure 1. Reduction by MV or DT causes the absorbance below $340 \mathrm{~nm}$ to decrease somewhat in intensity but to still impart a yellow cast to reduced apo MF solutions. Extensive dialysis either at $\mathrm{pH} 7$ or in $67 \%$ acetic acid (which dissociates the protein into subunits) does not result in loss of color from apo MF solutions, suggesting that the yellow color arises from a protein bound chromophore.

Fractional precipitation by $\mathrm{pH}$ adjustment or ammonium sulfate addition likewise demonstrated that the yellow color could not be separated from the apo MF protein. When monitored at $60,000 \mathrm{rpm}$ in a preparative centrifuge, apo MF at $70-100 \mathrm{mg} / \mathrm{ml}$ sedimented as a yellow front behind which was a colorless 
solvent zone with little protein present. Sedimentation velocity measurements at $48,000 \mathrm{rpm}$ at protein concentrations of $15-25 \mathrm{mg} / \mathrm{ml}$, following protein movement at $400 \mathrm{~nm}$, established two protein sedimentation bands. The heavier band (3-5\% of the total) moved at about twice the velocity as the major band ( $>95 \%)$ indicating the presence of a contaminating dimer (18). The sedimentation value of the major band was $15 \mathrm{~S}$, a value smaller that typically found (18) for apo MF (16-18s at zero protein concentration), but perhaps is due to the non ideality of these solutions at the high protein concentrations required to monitor protein movement at $400 \mathrm{~nm}$. Taken together, the results strongly indicate that the yellow color is an integral property of apo MF.

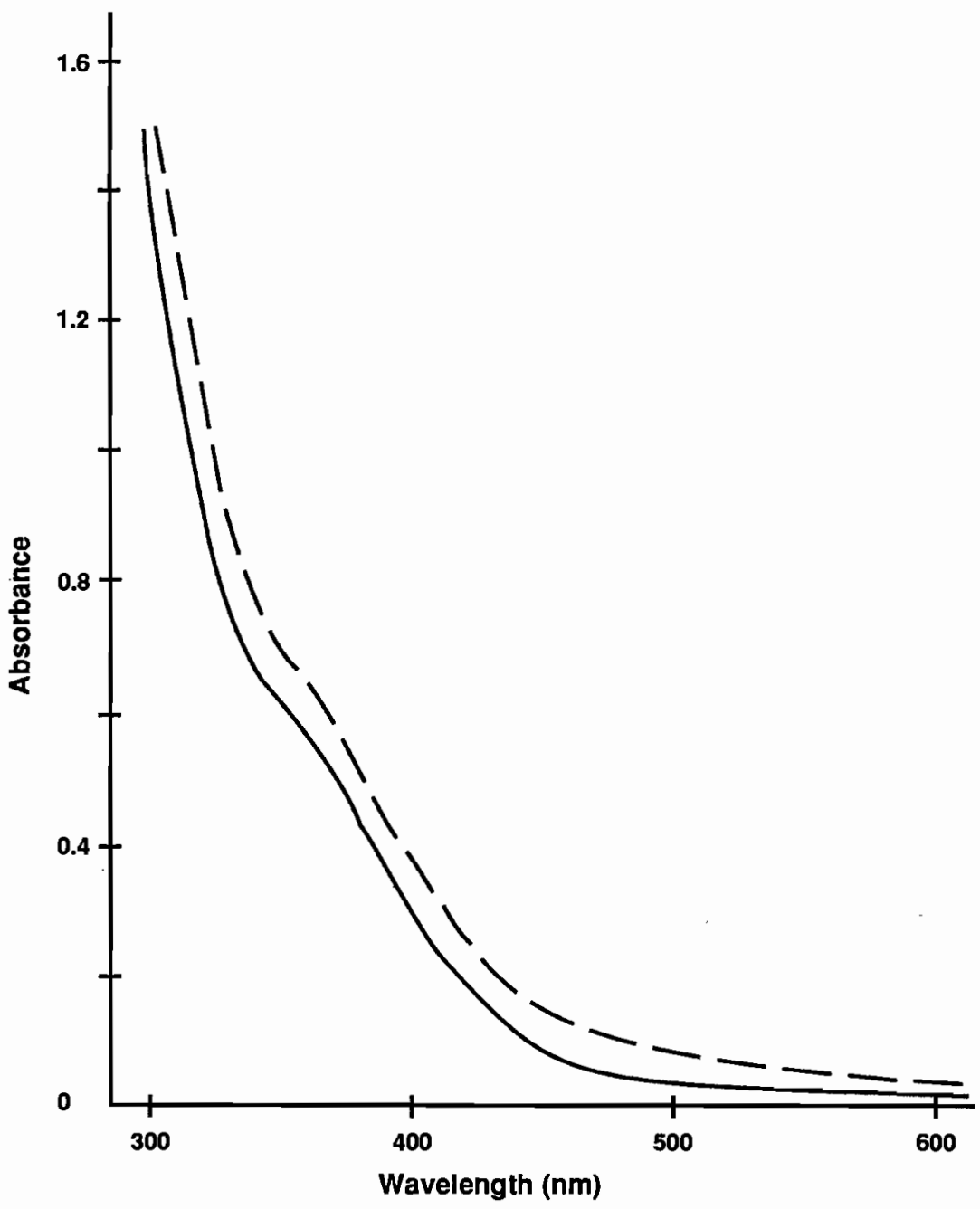

Figure 1. The optical absorption spectrum of apo MF (dashed line) and apo MF at the same concentration reduced anaerobically with methyl viologen (solid line). 
Figure 2 shows the results of controlled potential microcoulometry of anaerobic apo MF containing $<0.05 \mathrm{Fe} / \mathrm{apo} \mathrm{MF}$ as a function of applied potential. Apo MF undergoes a MV-mediated six electron reduction with a midpoint reduction potential of $-310 \mathrm{mv}$ vs. the normal hydrogen electrode (NHE). The E1/2 value is independent of $\mathrm{pH}$, excluding a proton-linked redox reaction.

Preliminary EPR measurements at $4.2 \mathrm{~K}$ of MV-reduced apo MF has indicated an easily power saturated $\mathrm{g}=2$ signal present in reduced apo $\mathrm{MF}$ which disappears upon exposure to air, conditions which produce oxidized apo MF.

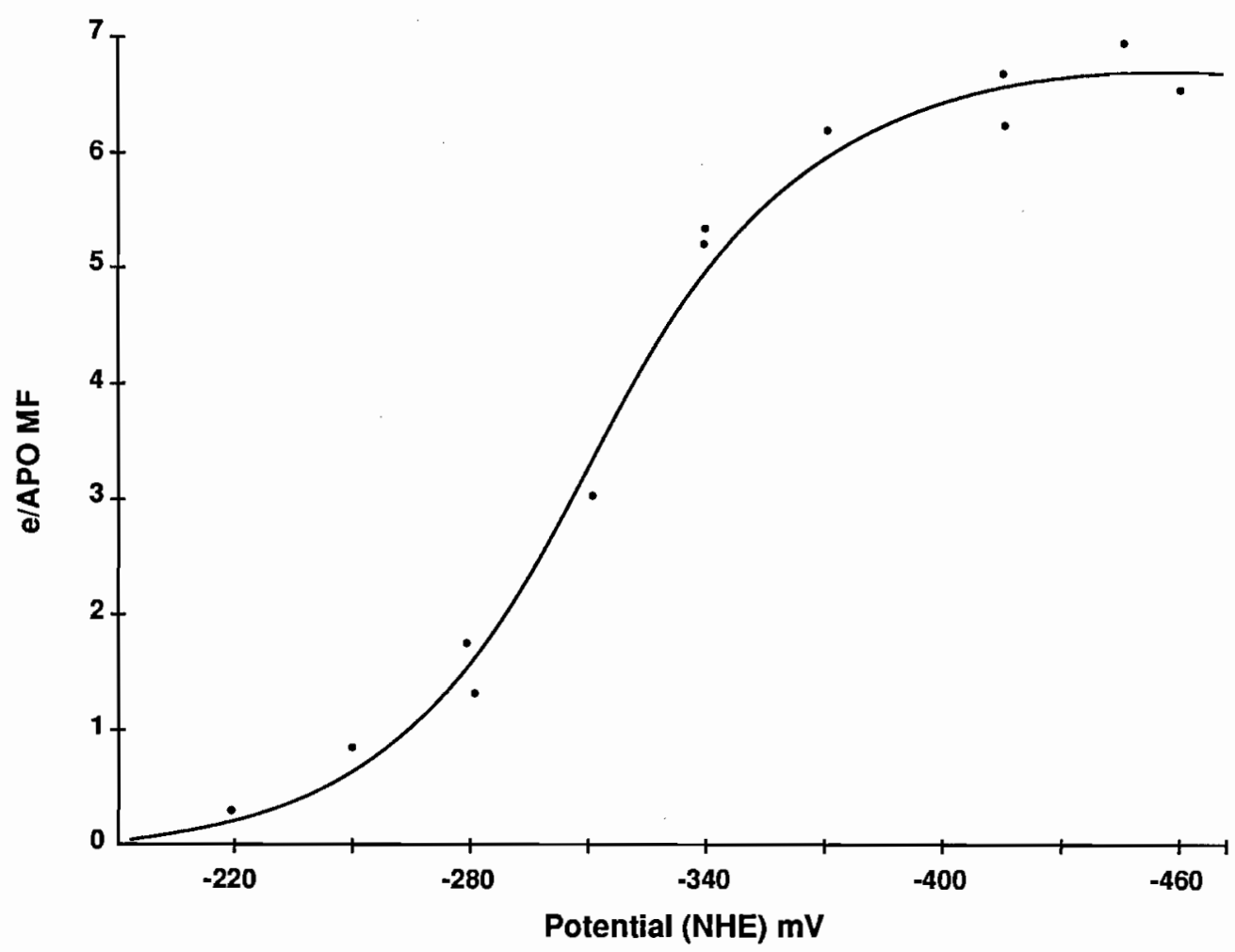

Figure 2. Microcoulometric reduction of apo $\mathrm{MF}$ in $0.025 \mathrm{M}$ Tes $\mathrm{pH} 7.25$ containing $0.1 \mathrm{mM}$ MV as a mediator. An $\mathrm{E} 1 / 2$ value of $-310 \mathrm{mV}$ and an $\mathrm{n}=1$ value were determined from the fit of the data points (solid line). A total of $6.75 \mathrm{e} / \mathrm{apo} \mathrm{MF}$ was obtained for total reduction of apo MF.

\section{DISCUSSION}

The experimental results support the hypothesis that apo mammalian ferritin has an inherent redox capacity. Figure 2 clearly shows that iron-free apo $\mathrm{MF}$ undergoes an $\mathrm{n}=1$ redox reaction with a midpoint potential of $-310 \mathrm{mv}$ 
vs. NHE, in which a total of 6-7 electrons are transferred to some acceptor within the apo MF protein. This reduction potential is invariant with variation in $\mathrm{pH}$, showing that proton transfer does not accompany electron transfer. This reduction process is responsible for the slight decrease in absorbance observed in Figure 1. Upon exposure to air, the reduced centers are reoxidized, establishing an operational electrochemical reversibility of the electron acceptor sites on apo MF.

We have also examined the effect of early mineral formation in the protein core on these electron acceptor sites in apo MF by adding 8,16 and 32 $\mathrm{Fe}^{2+}$ ions to apo $\mathrm{MF}$ and allowing oxidation by $\mathrm{O}_{2}$ to occur, thereby forming $\mathrm{Fe}^{3+}$ mineral cores with the indicated numbers of iron atoms. In all three cases, when microcolometric reduction was carried out, reduction of the iron containing proteins consisted of a transfer of electrons to the ferritin molecules equivalent to the number of iron atoms present plus about six electrons transferred to the acceptor sites on apo MF. For example, a total of 38.9 electrons were transferred to the apo MF protein to which $32 \mathrm{Fe}^{3+}$ had been added by $\mathrm{Fe}^{2+}$ oxidation, a result corresponding to a one electron reduction of each of the 32 iron atoms present plus a 6.9 electron reduction of the apo MF, itself. After this reduction, the bound iron could be chelated and quantitated with bipyridyl forming $\mathrm{Fe}$ (bipyd) $3^{2+}$, indicating that complete reduction of $\mathrm{Fe}^{3+}$ core iron had occured. The complete nature of the protein bound acceptor sites remains unclear at present although some insights are suggested from the properties of apo MF that we have measured here.

From the time of its initial preparation (19), reports have appeared regarding the presence of a yellow color in solutions of apo MF. While this property was reported (20) on one occasion as arising from an impurity (a conclusion supported in part by our results indicating the presence of a small amount of apo MF dimer), we have found evidence for it being an integral part of apo MF. The fractional precipitation results and the preparative and analytical sedimentation experiments strongly support the presence of a broadly absorbing, protein-bound chromophor, rather than a contaminant which likely would separate from the apo MF during the described treatments. This chromophor appears to be a result of or associated with the aromatic amino acids which absorb maximally at $280 \mathrm{~nm}$, but which tail off into the visible spectral region, thereby, imparting a yellow color to apo MF. The anamolous fluoresence behavior of apo MF (14) has been previously reported and explained as arising from rigidly immobilized, protein-bound aromatic amino acid side chains. Our results are consistent with this proposal.

The six-electron reduction of apo MF shown in Figure 2 appears to be related to the phenomenon responsible for the yellow color in apo MF because upon reduction, the yellow color decreases in intensity. In addition, preliminary low temperature EPR measurements of MV-reduced apo MF show the presence of a $g=2$ EPR signal, possibly a radical species formed upon reduction. A detailed and consistent explanation of the various properties of apo MF observed in this study is still being developed, but the results, when taken together, suggest that redox active centers exist in the protein shell of ferritin which may be utilized in electron transfer from external reagents to the iron atoms of the ferritin core, converting bound $\mathrm{Fe}^{3+}$ to more mobil $\mathrm{Fe}^{2+}$. Additional studies are underway to examine this possibility in futher detail. 


\section{ACKNOWLEDGEMENTS}

G.D.W. was supported by the Office of Naval Research. R.B.F. was supported by the National Science Foundation.

\section{REFERENCES}

1. Ford, G.C., Harrison,P.M., Rice, D.W., Smith, J.M.A, Treffry, A., White, J.L. and Yariv, J. (1984) Phil. Trans. R. Soc. Lond. B. 304, 551-565.

2. Aisen, P. and Listowsky, I. (1980) Annu. Rev. Biochem. 49, 375-393.

3. Theil, E. C. (1987) Annu. Rev. Biochem. 56, 289-315.

4. Crichton, R. R. and Charloteaux-Wauters, M. (1987) Eur. J. Biochem. 164, 485-506.

5. Treffry, A and Harrison, P.M. (1984) J. Inorg. Biochem. 21, 9-20.

6. Wardeska, J. G., Viglione, B. and Chasteen, N. D. (1986) J. Biol. Chem. 261, 6672-6683.

7. Jacobs, D., Watt, G. D., Frankel, R B. and Papaefthymiou, G. C: (1989) Biochemistry 28, 9216-9221.

8. Watt, G.D., Frankel, RB. and Papaefthymiou, G.C. (1985) Proc. Natl. Acad. Sci. USA. 82, 3640-3643.

9. Watt, G.D., Jacobs,D.B. and Frankel, RB. (1988) Proc. Natl. Acad. Sci. USA. 85, 7457-7461.

10. Jacobs, D.L., Watt, G.D., Frankel, R.B. and Papaefthymiou, G.C. (1989) Biochemistry 28, 1650-1655.

11. Frankel, R.B., Papaefthymiou, G.C. and Watt, G.D. (1987) Hyperfine Interactions, 33, 233-240.

12. Mayo, S.L., Ellis. W.R, Crutchley, RJ. and Gray, H.B. (1986) Science 233, 984-990.

13. Mc Lendon, S.L. (1988) Acc. Chem. Res. 21, 160-167.

14. Stephanini, S., Chiacone, E., Arosio, P., Finazzi-Agro, A and Antonini, E. (1982) Biochemistry 21, 2293-2299.

15. Listowsky, I., Blauer, G., Englard, S. and Betheil, J.J. (1972) Biochemistry, 11, 2176-2182.

16. Treffery, A and Harrison, P (1978) Biochem. J. 171. 313-317.

17. Watt, G. D. (1979) Anal. Biochem. 99, 399-407.

18. Bjork, I. (1973) Eur. J. Biochem. 36. 178-184.

19. Granick, S. and Michaelis, L. (1943) J. Biol. Chem. 147, 91-97.

20. Bjork, I. and Fish, W. W. (1971) Biochemistry 10, 2844-2848. 